\title{
OPEN Electrocatalytic study of NiO-MOF with activated carbon composites for methanol oxidation reaction
}

\begin{abstract}
Saadia Hanif ${ }^{1}$, Naseem Iqbal ${ }^{1 凶}$, Tayyaba Noor ${ }^{2}$, Neelam Zaman $^{1} \&$ K. Vignarooban ${ }^{3}$
In this work, the methanol oxidation reaction is investigated on Ni based metal organic frameworks (MOF) and its composites with biomass derived activated carbon. NiO-MOF and composites with activated carbon were synthesized using hydrothermal method. SEM, EDX, and XRD, FTIR, TGA techniques were used for characterization of composites. The electrochemical activity of catalysts for oxidation of methanol was tested using cyclic voltammetry (CV) in $1 \mathrm{M} \mathrm{KOH}$ and $3 \mathrm{M} \mathrm{CH}_{3} \mathrm{OH}$ on glassy carbon electrode in three electrode setup. The electrochemical performance shows the effect of activated carbon concentration on methanol oxidation. The electro-oxidation catalyzed by NiO-MOF with activated carbon $\left(40 \mathrm{mg}\right.$ ) composite exhibits a peak current density of $182.72 \mathrm{~mA} / \mathrm{cm}^{2}$ at $0.89 \mathrm{~V}$ potential with a scan rate of $50 \mathrm{mV} / \mathrm{s}$ making it a potential catalyst for electrocatalysis of methanol.
\end{abstract}

The global energy crisis, impending energy reserves and the deteriorating environment calls for alternative green energy. In addition, sustainable and proficient energy conversion technologies are extremely needed because of the rapid diminution of fossil fuels and the immense apprehension of human society about environmental pollution. In order for intermittent energy generation technologies to strengthen their foothold, energy storage solutions need to become better performing and economically viable. Implementation of fuel cell technologies has been greatly encouraged for suppressing the emission of carbon dioxide ${ }^{1}$. Various sources have been explored to deliver sustainable, environmentally friendly and inexpensive energy. Fuel cells deem ideal candidates meeting all these requirements ${ }^{2}$.

Various materials can be used as catalysts such as platinum and platinum alloys ${ }^{3,4}$. However, platinum and its alloys being expensive metals increase the overall cost of the fuel cell. In the recent years research has been shifted finding alternative catalysts with high activity, high stability and low cost ${ }^{5}$. Zhao et al. reported star like $\mathrm{Pt}-\mathrm{Cu} / \mathrm{rGO}$ nanoparticles as electrocatalysts for methanol oxidation. The reported nanoparticles show a density of $40.2 \mathrm{~mA} / \mathrm{mg}$ at $50 \mathrm{mV} / \mathrm{s}$ scan rate in $1 \mathrm{M} \mathrm{CH}_{3} \mathrm{OH}$ and $0.5 \mathrm{M}$ of $\mathrm{H}_{2} \mathrm{SO}_{4}{ }^{6}$. Moreover, Qiu et al. reported platinum and graphene nanocomposites for methanol oxidation. The reported composite show $2.53 \mathrm{~mA} / \mathrm{cm}^{2}$ current density at a scan rate of $10 \mathrm{mV} / \mathrm{s}$ in $1 \mathrm{M} \mathrm{H}_{2} \mathrm{SO}_{4}$ and $2 \mathrm{M} \mathrm{CH}_{3} \mathrm{OH}$ solution ${ }^{7}$. Recently, a new family of porous solids called porous coordination polymers or metal organic frameworks (MOFs) are becoming popular as electrocatalysts for fuel cells ${ }^{8}$. Typically, MOFs are formed by combining metals and ligands through coordination bond. They are characterized by maximum degree of crystallinity, porosity; high surface area and pore size clearly going beyond that of other porous materials ${ }^{9}$. Researchers have discovered that small alteration to functional groups located on the linkers can greatly enhance potential properties of MOFs; for example in drug delivery, heterogeneous catalysis, gas storage, separation and so on ${ }^{10}$. Application of MOFs in catalysis are determined on the basis of successfully developed synthetic principles; which include catalyst encapsulation in framework, stabilization of catalytically functioning nanosized particles, heterogenization of corresponding catalysis, post synthesis insertion of catalytic metal site and alliance of catalysis with chemical separation ${ }^{11}$.

Carbon based electrocatalysts have shown promising portfolios over the years. They provide good mechanical strength, increased active surface area, and enhanced conductivity at a lower cost. The problem however is their low activity. So, composites of carbon based materials are made with other established electrochemically active materials such as MOFs. MOFs are crystalline materials with high porosity and high activity ${ }^{12,13}$. Their activity and stability can be enhanced by the incorporation of carbon ${ }^{14}$. Mehek et al. reported Co-MOF-71, and CoMOF-71/GO composites. Their appreciable high current density makes them promising substitutes to the other expensive electrocatalysts for various fuel cell applications. They show current density of $29.1 \mathrm{~mA} / \mathrm{cm}^{2}$ at $50 \mathrm{mV} / \mathrm{s}$. The appreciable electrocatalytic activity and stability of prepared material for methanol oxidation was associated

${ }^{1}$ USPCAS-E, National University of Sciences and Technology, Islamabad 44000, Pakistan. ${ }^{2}$ SCME, National University of Sciences and Technology, Islamabad 44000, Pakistan. ${ }^{3}$ Department of Physics, Faculty of Science, University of Jaffna, Jaffna 40000, Sri Lanka. ${ }^{\circledR}$ email: naseem@uspcase.nust.edu.pk 
with the corresponding effect of Co-MOF and graphene oxide ${ }^{15}$. Noor et al. reported NiO-MOF and 1-5, 8 wt $\%$ rGO NiO-MOF composites. Among all the composites studied by them, $5 \mathrm{wt} \% \mathrm{rGO}$ NiO-MOF show superlative current density of $285.73 \mathrm{~mA} / \mathrm{cm}^{2}$ at $50 \mathrm{mV} / \mathrm{s}$ in $3 \mathrm{M}$ methanol and $1 \mathrm{M} \mathrm{NaOH}$ solution ${ }^{16}$. Yaqoob et al. reported Ni-BTC MOF and its composites of 1-5 and $8 \mathrm{wt} \% \mathrm{rGO}$ for methanol oxidation. The best results were obtained for Ni-BTC/4 wt\% rGO of about $200.22 \mathrm{~mA} / \mathrm{cm}^{2}$ given $0.69 \mathrm{~V}$ and $50 \mathrm{mV} / \mathrm{s}$ in $2 \mathrm{M} \mathrm{CH}_{3} \mathrm{OH}$ solution with $1 \mathrm{M} \mathrm{NaOH}$ as support electrolyte. Besides, with the increase in the amount of catalyst, the current density is gradually increased until $2 \mathrm{mg}$, which was recognized as an ideal concentration for electrochemical testing ${ }^{17}$.

In this work, we report nickel based metal organic framework and its composite with biomass derived activated carbon $(\mathrm{AC})$ as efficient catalytic material for methanol oxidation reaction. The work focuses on electrocatalytic studies of NiO-MOF and its composites with AC in alkaline media. All the prepared series of metal organic framework composites exhibit exceptional high electrocatalytic activity with AC to enhance the conductivity of catalyst.

\section{Experimental}

All reagents and chemicals were purchased from Sigma-Aldrich with superlative quality and used without further alteration. The chemicals used were nickel nitrate hexa hydrate $\left(\mathrm{NiNO}_{3} \cdot 6 \mathrm{H}_{2} \mathrm{O}\right)$, benzene di-carboxylic acid (terephthalic acid), $N, N$-dimethylformamide (DMF), triethylamine (TEA) and phosphoric acid $\left(\mathrm{H}_{3} \mathrm{PO}_{4}\right)$.

Synthesis of NiO-MOF. NiO-MOF was synthesized from the already reported method ${ }^{17}$. In $100 \mathrm{ml}$ of DMF and $0.41 \mathrm{~g}$ of terephthalic acid was dissolved by stirring. Then, few drops of triethyl amine was added in the solution. The Nickel nitrate hexahydrate $(0.61 \mathrm{~g})$ was then added, and the resulting solution was stirred for $30 \mathrm{~min}$. The prepared solution was poured into an autoclave (Teflon lined) and heated at $120^{\circ} \mathrm{C}$ for $24 \mathrm{~h}$ in an oven. The crystals of NiO-MOF were collected through filtration, repeatedly washed with DMF to washout extra organic materials followed by drying in vacuum oven at $80^{\circ} \mathrm{C}$.

Synthesis of activated carbon from waste. Fallen waste leaves of Lantana plant were collected from garden and washed thoroughly to remove all impurities. After proper drying, leaves were grinded to reduce its size until it can pass through a mesh size of 200 microns. Then, the obtained powder sample was dissolved in a solution of diluted phosphoric acid $\left(\mathrm{H}_{3} \mathrm{PO}_{4}\right)$ for $16 \mathrm{~h}$. It was then calcined at a temperature of $550{ }^{\circ} \mathrm{C}$ to activate it, as this temperature results in increasing carbon burn-off and evaluation of volatiles from the samples ${ }^{18}$. Acid wash/neutralization was done with distilled water to remove any unreacted acid and neutralize the $\mathrm{pH}$ of the solution up to 6-7. Resulting AC was then dried and stored for further use ${ }^{15}$. The plant material used in this research comply with relevant institutional, national, and international guidelines and legislation.

Synthesis of NiO-MOF @ AC composites. In $100 \mathrm{ml}$ of DMF, terephthalic acid (0.41 g) was dissolved by stirring. Then, few drops of triethyl amine was added in the solution. The Nickel nitrate hexahydrate $(0.61 \mathrm{~g})$ was then added in the solution and the resulting solution was stirred for $30 \mathrm{~min}$. Activated carbon (10-60 mg) was added into the solution and stirred for $2 \mathrm{~h}$. The prepared solution was poured into an autoclave (Teflon lined) and heated at $120^{\circ} \mathrm{C}$ for $24 \mathrm{~h}$ in an oven. The crystals of NiO-MOF@AC were collected through filtration, repeatedly washed with DMF to washout extra organic materials followed by drying in vacuum oven at $80{ }^{\circ} \mathrm{C}$ Fig. 1 shows the schematic of preparation steps for NiO-MOF @AC composites.

Characterization of catalysts and elemental analysis. Scanning Electron Microscopy (SEM) was done with VEGA3 TESCON at different resolutions and voltage of $20 \mathrm{kV}$ to study surface morphologies. Energy dispersive spectroscopy equipped with SEM was also used to study the elemental analysis of composite at three different spots. X-ray powder diffractometer (XRD STOE Germany) was used to observe the crystal lattice of composite. XRD machine is linked with a computer interface having $\mathrm{Cu} \mathrm{Ka}$ at $\lambda=1.5418 \AA$ and the diffraction angle $2 \theta$ was varied at a range of $5-70^{\circ}$ with a step size of $4^{\circ} \mathrm{s}^{-1}$. With the help of Perkin spectrum 100 FT-IR spectrophotometer Metal ligand co-ordination was proved at the wave number range of $500-4000 \mathrm{~cm}^{-1}$. Thermo-gravimetric analysis (TGA) was employed by means of DTG-60H to test the thermal stability of composites such as $\mathrm{NiO}-\mathrm{MOFAC}(40 \mathrm{mg})$ in a nitrogen atmosphere.

Electrochemical evaluation. The electrochemical measurements were done by using Gamry instrument Reference 3000/3000 equipped with data acquisition software version of 7.06. Electrochemical activity of prepared catalysts was tested via cyclic voltammetry $(\mathrm{CV})$ in $1 \mathrm{M} \mathrm{KOH}$ and $3 \mathrm{M} \mathrm{CH}_{3} \mathrm{OH}$ by using three electrode set-up. In this set-up, glassy carbon, silver/silver chloride $(\mathrm{Ag} / \mathrm{AgCl})$ and $\mathrm{Pt}$ wire were used as the working electrode, reference electrode, and the counter electrode, respectively. Methanol and $\mathrm{KOH}$ were used as a fuel and supporting electrolyte, respectively. $5 \mathrm{wt} \%$ Nafion solution and ethanol were used as the binding agent and solvent, respectively. The CV study was first performed with glassy carbon electrode (GCE) without any catalytic material and next the set-up was run with GCE coated with catalytic material. Electrochemical impedance spectroscopic (EIS) study was conducted by using same three electrode set-up mentioned above in $3 \mathrm{M} \mathrm{CH}_{3} \mathrm{OH}$ and $1 \mathrm{M} \mathrm{KOH}$, under potentiostatic mode. The range of the frequency was set from 10 to $40 \mathrm{kHz}$ with an amplitude of $0.015 \mathrm{~V}$.

Electrode fabrication. For CV and EIS measurements, a catalyst ink was prepared by mixing the catalytic material $(2 \mathrm{mg})$, ethanol $(100 \mu \mathrm{L})$ and Nafion (5 wt\% solution) $(20 \mu \mathrm{L})$. The mixture was mixed thoroughly, and 


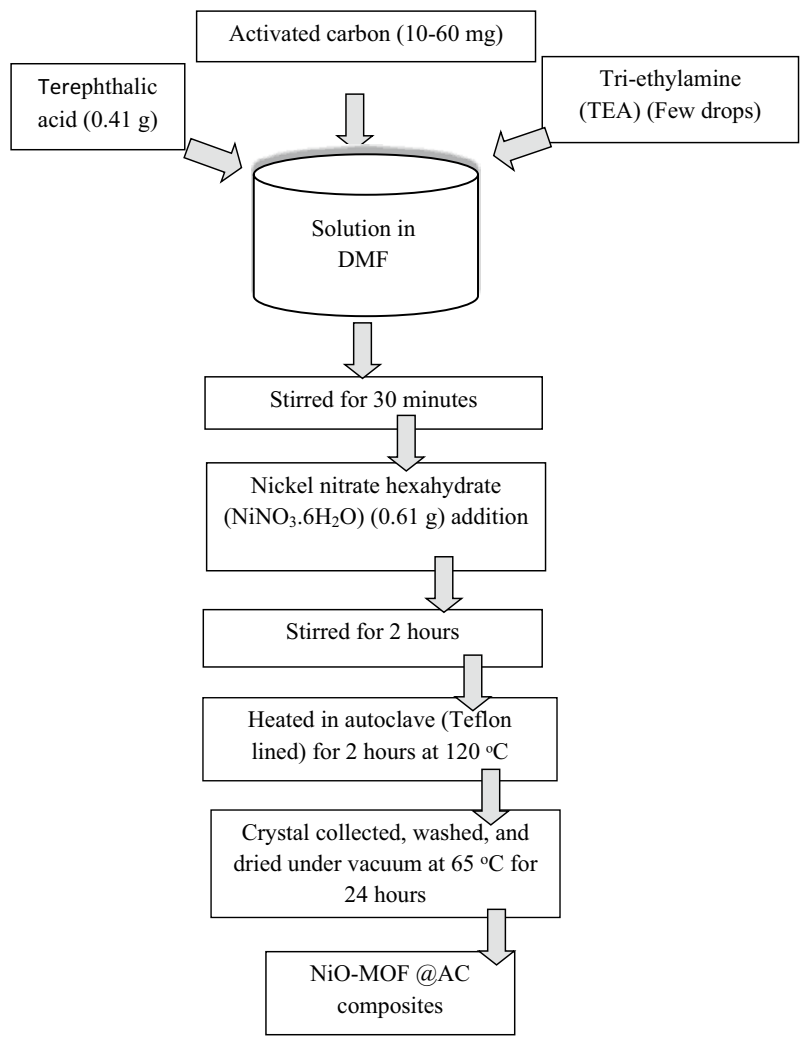

Figure 1. Schematic of preparation steps for NiO-MOF @AC composites.

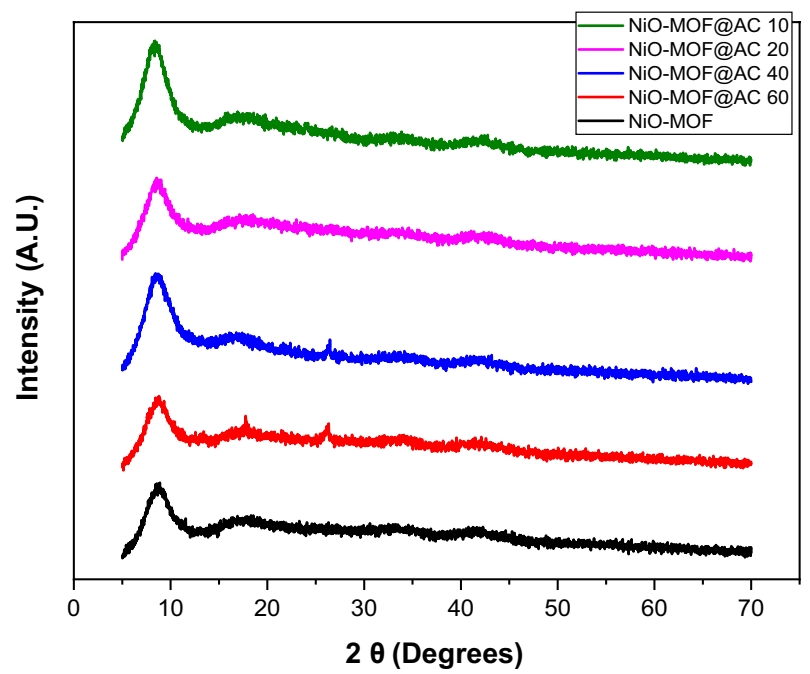

Figure 2. Powder XRD of $\mathrm{NiO}-\mathrm{MOF}$ and its composites with activated carbon.

then as prepared catalyst ink $(15 \mu \mathrm{L})$ was deposited on GCE by micropipette. Before each electrochemical measurement, the modified electrode was dried at room temperature.

\section{Results and discussion}

For detailed crystal structure, XRD study was carried out for all NiO-MOF and activated carbon composites, i.e., NiO-MOF@AC 10, NiO-MOF@AC 20, NiO-MOF@AC 40, NiO-MOF@AC 60 (Fig. 2). All the composites have retained the characteristic peak of $\mathrm{NiO}-\mathrm{MOF}$ at 10 degree. A low intensity peak at 26 degrees corresponds to the carbon and a characteristic peak at 44.7 corresponds to nickel oxide (NiO JCPDS card No. \#04-0835) ${ }^{19-21}$.

Figure 3 shows the FTIR absorbance spectra of NiO-MOF, and its activated carbon based composites such as NiO-MOF@AC 10,NiO-MOF@AC 20,NiO-MOF@AC 40 and NiO-MOF@AC 60. In all the prepared 


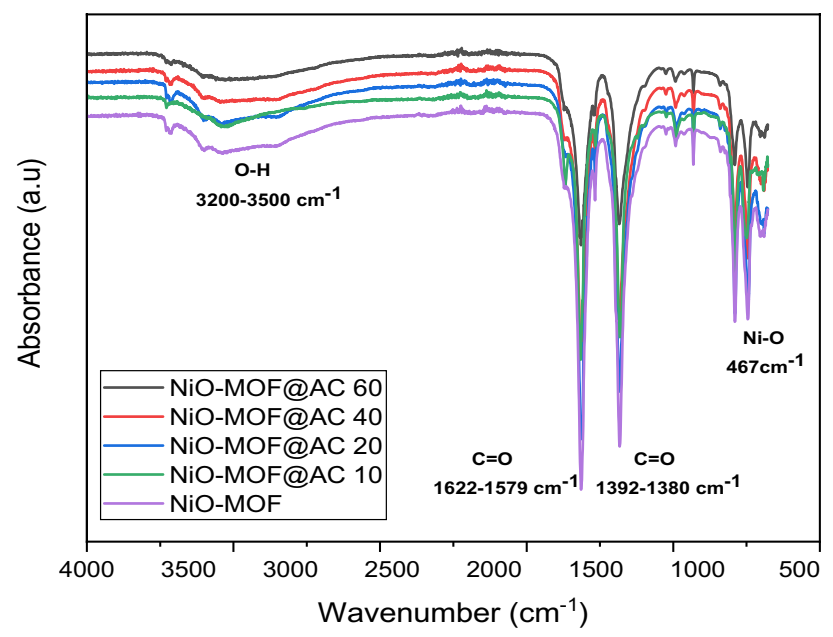

Figure 3. FTIR spectra of NiO-MOF and its composites with activated carbon.
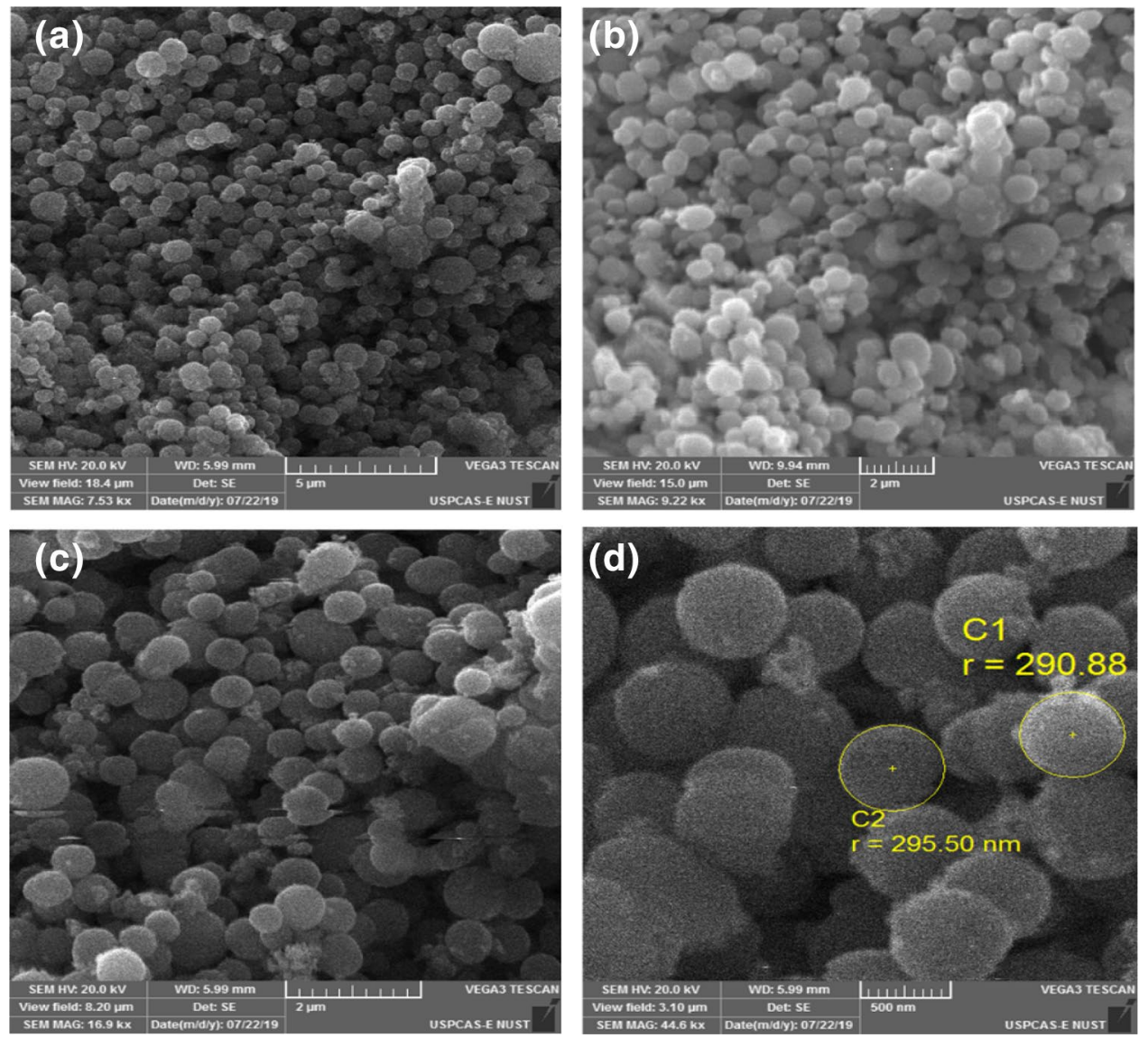

Figure 4. SEM images of NiO-MOF@AC 40.

electrocatalysts, the presence of broad peak between 3200 and $3500 \mathrm{~cm}^{1}$ shows the hydroxyl group $\left(\mathrm{OH}^{-1}\right)$ presence and the sharp band at $1392-1380 \mathrm{~cm}^{-1}$ and $1622-1579 \mathrm{~cm}^{-1}$, shows the presence of $\mathrm{C}=\mathrm{O}$ symmetric and asymmetric stretching vibrations. Further, the deprotonation of functional group, i.e. -COOH in benzene dicarboxylic acid is confirmed via absence of strong absorption peak at $1715-1680 \mathrm{~cm}^{-1}$. Besides, $\mathrm{Ni}-\mathrm{O}$ stretching band appear at $467 \mathrm{~cm}^{-130}$, proves the metal-ligand linkage. Thus, the absorption spectra of the prepared composites agree with the successful synthesis of NiO-MOF and its activated carbon based composites ${ }^{31}$.

Morphology of NiO-MOF@AC 40 was studied with the help of SEM and shown in Fig. 4. The SEM images show spherical structure with a mean diameter of $600 \mathrm{~nm}$ for the NiO-MOF@AC 40. The activated carbon particles can also be seen incorporated between the spherical structures of NiO-MOF. Table 1 shows the EDX 


\begin{tabular}{|l|l|l|l|l|l|}
\hline Sample/elements & NiO-MOF & NiO-MOF@AC 10 & NiO-MOF@AC 20 & NiO-MOF@AC 40 & NiO-MOF@AC 60 \\
\hline C wt\% & 33.01 & 41.78 & 44.87 & 46.19 & 49.88 \\
\hline O wt\% & 41.02 & 40.20 & 39.12 & 38.83 & 37.93 \\
\hline Ni wt\% & 25.97 & 18.02 & 16.01 & 14.98 & 12.19 \\
\hline
\end{tabular}

Table 1. EDX analysis of NiO-MOF and its composites with activated carbon.

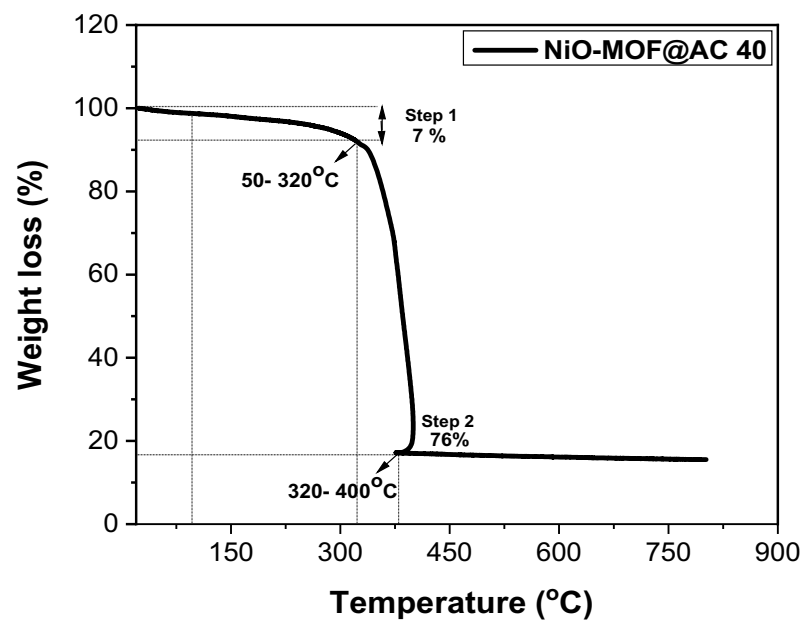

Figure 5. TGA analysis of NiO-MOF@AC 40 measured under $\mathrm{N}_{2}$ environment.

analysis of NiO-MOF and its composites with activated carbon such as NiO-MOF@AC 10, NiO-MOF@AC 20, NiO-MOF@AC 40 and NiO-MOF@AC 60 shows the presence of oxygen and carbon along with nickel. Likewise, the elemental content of carbon increases consequently with activated carbon, assigning the efficacious assimilation of activated carbon in MOF.

Figure 5 shows the TGA data of prepared composite NiO-MOF@AC 40 measured in a nitrogen atmosphere. TGA curve illustrate the weight loss of $7 \%$ till $320^{\circ} \mathrm{C}$ and can be attributed to the evaporation of adsorbed water molecules roughly between 50 and $320^{\circ} \mathrm{C}$. In the temperature range of $320-400{ }^{\circ} \mathrm{C}$, the second weight loss is appearing that is up to $76 \%$ ensuing from the decomposition of organic ligands. After $400{ }^{\circ} \mathrm{C}$, the weight of the NiO-MOF@AC 40 is found to be relatively stable. The elevated thermal stability of prepared activated carbon based composite can be ascribed to the coordinative linked interpenetrated framework ${ }^{22,23}$.

Electrochemical performance of NiO-MOF@AC composites was tested by using cyclic voltammetry in $1 \mathrm{M}$ $\mathrm{KOH}$ and $3 \mathrm{M} \mathrm{CH}_{3} \mathrm{OH}$ at $50 \mathrm{mV} / \mathrm{s}$ for oxidation of methanol. The NiO-MOF with activated carbon composites exhibited more catalytic activity towards methanol oxidation reaction (see Fig. 6). In case of NiO-MOF modified GCE, the peak current density was $140 \mathrm{~mA} / \mathrm{cm}^{2}$ and by the addition of activated carbon, the peak current density increases gradually. The sample with greater concentration of activated carbon $(40 \mathrm{mg})$ shows highest peak current density of $182.71 \mathrm{~mA} / \mathrm{cm}^{2}$ at $50 \mathrm{mV} / \mathrm{s} \mathrm{scan}$ rate. The other composites show peak current density values of 142.12 and $164 \mathrm{~mA} / \mathrm{cm}^{2}$ for $10 \mathrm{mg}$ and $20 \mathrm{mg}$ activated carbon, respectively at a scan rate of $50 \mathrm{mV} / \mathrm{s}$. With further increase in the amount of activated carbon $(60 \mathrm{mg})$, the peak current density decreases to $166.28 \mathrm{~mA} /$ $\mathrm{cm}^{2}$. In summary, it is suggested that current density can be enhanced by increased concentration of activated carbon to a certain limit; however, augmented concentration of activated carbon might have an undesirable consequence on catalytic activity too ${ }^{24,25}$. Moreover, the CV curves have different shape and peak position for NiO-MOF@AC composites, is because of activated carbon incomplete dispersion at the time of synthesis and also due to its high quantity usage the clustering of the catalyst occurs that results in covering of MOF surface $\mathrm{e}^{25}$, thus impeding the active catalytic sites to carry out the reaction at low potential value and consequently charge transfer happen at high potential ${ }^{15}$.

The linear relationship of peak current densities of composites such as NiO-MOF@AC 10, NiO-MOF@AC 20, NiO-MOF@AC 40,NiO-MOF@AC 60 with scan rate is shown in Fig. 7. The figure describes the effect of scan rate, i.e., $50-200 \mathrm{mV} / \mathrm{s}$ on peak current density; with increasing scan rate, the peak current density also increases gradually. The reason for high current density at higher scan rate is due to non-electroactive species are not oxidized or reduced into the product ${ }^{26}$. Thus, high current density is obtained due to the formation of electroactive products. By analyzing the results, it can be figured out that increasing the scan rate i.e., $50 \mathrm{~m}-200 \mathrm{mV} / \mathrm{s} \mathrm{for}$ all the composites can lead to corresponding increase in current density as well. This response of the catalytic material is associated with the enhanced extent of the reaction ${ }^{27}$. Table 2 compares the properties of prepared catalysts with other catalysts reported in the literature. 


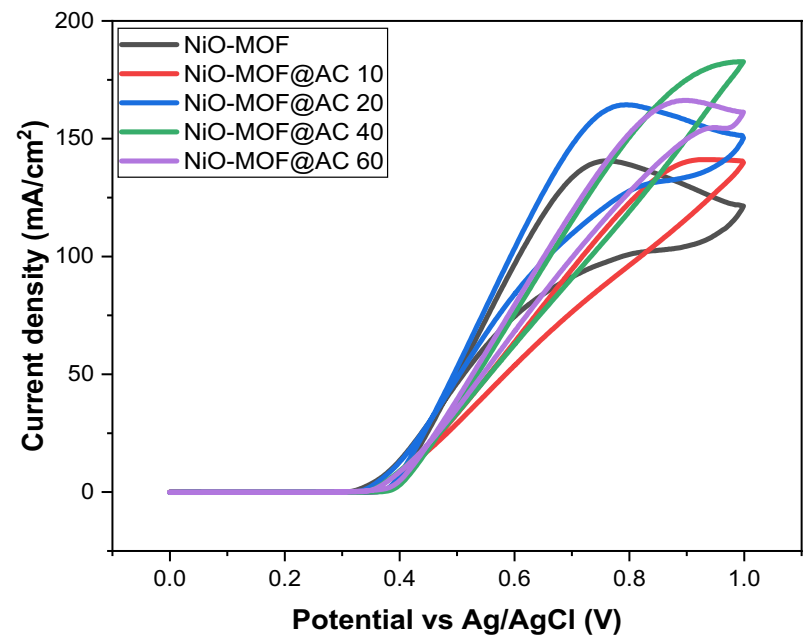

Figure 6. Cyclic voltammogram of $\mathrm{NiO}-\mathrm{MOF}$ and composites with activated carbon in $1 \mathrm{M} \mathrm{KOH}$ and $3 \mathrm{M}$ methanol.

Peak current density and square root of scan rate is proportional to each other suggesting a diffusion-controlled process in correspondence with Randles-Sevick equation (given below with usual notations) as demonstrated in Fig. $8^{30}$.

$$
\mathrm{I}_{\mathrm{p}}=\left(2.99 \times 10^{5}\right) \mathrm{n}\left(\alpha \mathrm{n}_{\mathrm{a}}\right) \mathrm{ACD}^{1 / 2} \mathrm{v}^{1 / 2}
$$

where Ip $=$ Current in Amperes, $\mathrm{n}_{\alpha}=$ No of electrons involved in rate determining step, $\mathrm{A}=$ Surface area of electrode $\left(0.07065 \mathrm{~cm}^{2}, \mathrm{n}=\right.$ No of electrons transferred in process, $\mathrm{D}=$ Diffusion co-efficient $\left(\mathrm{cm}^{2} / \mathrm{s}\right), \mathrm{C}=$ Concentration in mole $/ \mathrm{cm}^{3} \mathrm{~V}=$ Scan rate in $\mathrm{V} / \mathrm{s}$.

Formula used to calculate $\alpha$ is as under

$$
\mathrm{Ep}-\mathrm{Ep} / 2=1.857 \mathrm{RT} / \mathrm{nF} \alpha
$$

Ep $=$ Peak potential, $R=$ General gas constant $(8.3143 \mathrm{~J} / \mathrm{k} / \mathrm{mole}), \mathrm{T}=298 \mathrm{k}, \mathrm{n}=$ No of electrons transferred in process, $\mathrm{F}=$ Farad's constant $(96,580), \alpha=$ Charge transfer co-efficient.

For all the prepared catalysts, the diffusion coefficient (D) is calculated as $1.171 \times 10^{-3}, 1.174 \times 10^{-3}, 1.37 \times 10^{-3}$, $1.78 \times 10^{-3}$ and $1.42 \times 10^{-3}$ for NiO- MOF, NiO-MOF@AC 10, NiO-MOF@AC 20, NiO-MOF@AC 40 and, NiOMOF@AC 60, respectively. All these diffusion coefficient values keep the methanol oxidation that followed a diffusion controlled mechanism ${ }^{31}$.

Tafel plots are represented in Fig. 9 derived from cyclic voltammogram. Overpotential is calculated via formula $\mathrm{E}-\mathrm{E}_{\mathrm{o}}{ }^{32}$. Commercial Pt/C catalyst shows these curves at or near $0.0 \mathrm{~V}$ but other materials give higher voltages. In this study, NiO-MOF@AC 40 composite displays a curve at lower overpotential. The improved overpotential at lower value represents its superior electrocatalytic activity, so less activation energy is required. With the composite formation with activated carbon, more surface improvement is achieved in the terms of pores. Due to these pores more ions can be incorporated at lower potentials. This results in increased kinetics with decreased activation energy for methanol oxidation ${ }^{33,34}$.

In addition, Tafel slopes at $0.55 \mathrm{~V}$ of potential were calculated for the study reaction kinetics of the catalytic process and listed in Table 3. Tafel slopes for NiO-MOF and its activated carbon based composites such as NiOMOF@AC 10,NiO-MOF@AC 20,NiO-MOF@AC 40 and NiO-MOF@AC 60 are in the range of 121-185 mV/ dec. The slopes at lower potential might suggest the first $\mathrm{C}-\mathrm{H}$ bond breaking in methanol and first electron transfer that designates the rate-determining $\operatorname{step}^{35,36}$.

The electrochemical impedance spectroscopy (EIS) is another excellent technique to analyze the activity of modified electrode. Here, the electrochemical impedance was measured by using potentiostatic mode in the same three electrode set-up in $1 \mathrm{M} \mathrm{KOH}$ and $3 \mathrm{M}$ methanol with bare and modified GCE and the corresponding Nyquist plots are shown in Fig. 10. These Nyquist plots show that as the amount of activated carbon in NiO-MOF increase, the charge transfer resistance decreases dramatically which is a clear indication of facilitation of charge transfer for the catalytic conversion of methanol ${ }^{37-40}$. The same has been concluded from voltammetry studies as mentioned above. The impedance results complement the voltametric findings. Moreover.

In order to extract EIS data, the model of electrochemical electrical circuit (EEC) with charge transfer resistance, solution resistance, capacitance, and Warburg diffusion co-efficient was best fitted on actual data extracted EIS data is given in Table 4. Firstly, in high to average frequency region a semicircle appear that not only provide the information about methanol partial oxidation but also give knowledge about Rct (a resistance at electrolyte/ electrode boundary) and approve that system response is primarily controlled via charge transfer process by means of pores of electrode material. Moreover, the Warburg diffusion co-efficient is obtainable through slope $\left(45^{\circ}\right)$ in low frequency domain is associated with charge transfer activity and its minimal value prove that reaction go on all through diffusion controlled phenomena ${ }^{38-40}$. 
(a)

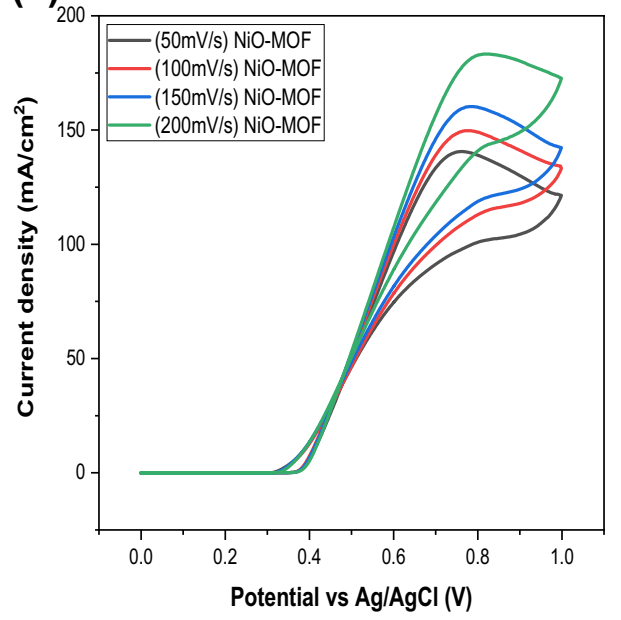

(c)

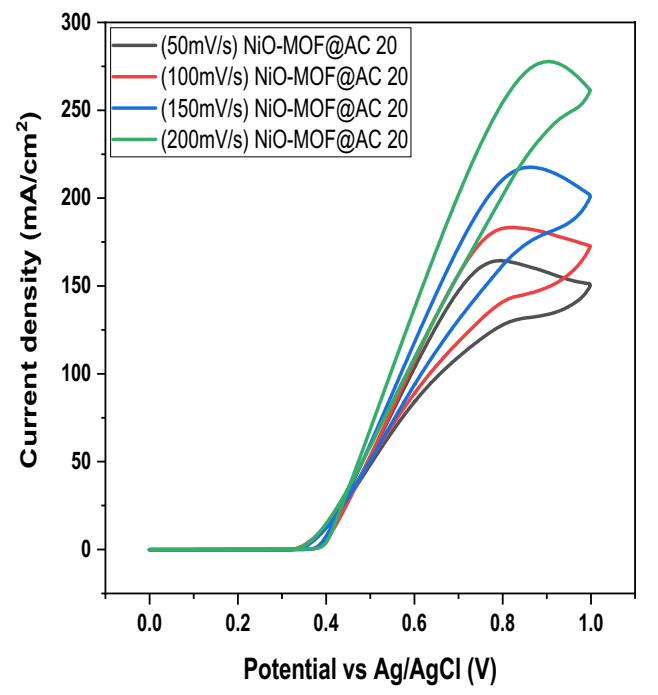

(b)

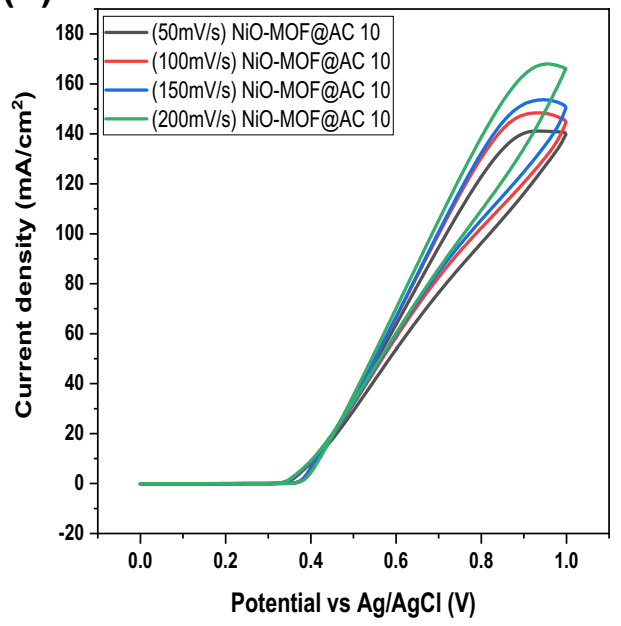

(d)

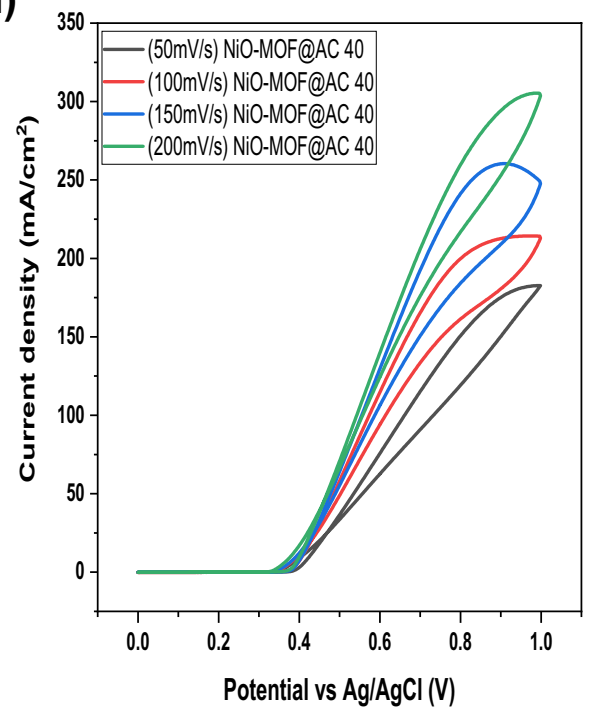

(e)

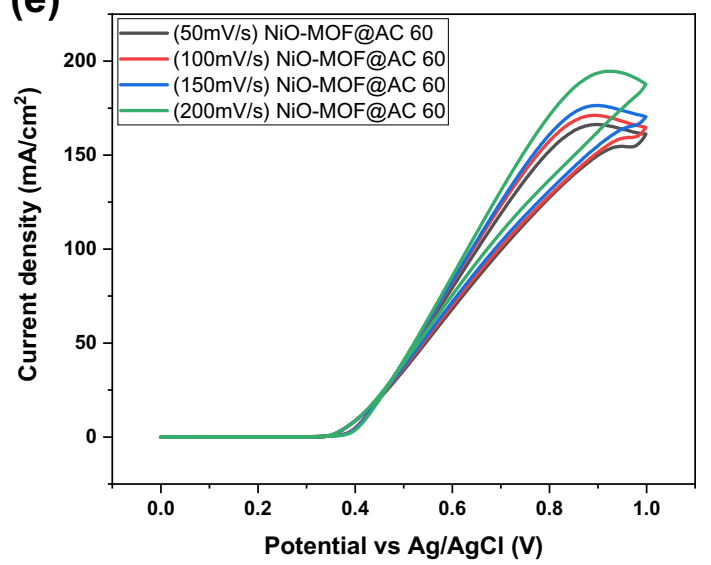

Figure 7. Cyclic voltammogram of (a) NiO-MOF, (b) NiO-MOF@AC 10, (c) NiO-MOF@AC 20, (d) NiOMOF@AC 40, (e)NiO-MOF@AC 60.

Chronoamperometry was used to find the percentage stability of the prepared composites at $0.8 \mathrm{~V}$ of potential with similar electrode set-up in $1 \mathrm{M} \mathrm{KOH}$ and $3 \mathrm{M}$ methanol solution and the results are shown in Fig. 11. It can be realized that quickly after the reaction starts, the current value falls to a specific value which is due to formation 


\begin{tabular}{|l|l|l|l|l|l|}
\hline Sr. no & Catalyst & MeOH conc. $(\mathrm{M})$ & Scan rate $(\mathbf{m V} / \mathbf{s})$ & Current density $\left(\mathbf{m A} / \mathbf{c m}^{2}\right)$ & Ref. \\
\hline 1 & Co-MOF & 3 & 50 & 10.4 & 15 \\
\hline 2 & $5 \mathrm{wt} \% \mathrm{GO} / \mathrm{Co}-\mathrm{MOF}$ & 3 & 50 & 29.10 & 15 \\
\hline 3 & $\mathrm{ZnO}_{(40 \%)} / \mathrm{CeO}_{2(60 \%)}$ dots@CNFs & 3 & 50 & 16.3 & 28 \\
\hline 4 & $\mathrm{Cu}-\mathrm{MOF}$ & 3 & 50 & 48.55 & 29 \\
\hline 5 & $5 \mathrm{wt} \% \mathrm{GO} / \mathrm{Cu}-\mathrm{MOF}$ & 3 & 50 & 120 & 29 \\
\hline 10 & NiO-MOF & 3 & 50 & 140.59 & This work \\
\hline 11 & NiO-MOF@AC 10 & 3 & 50 & 142.12 & This work \\
\hline 12 & NiO-MOF@AC 20 & 3 & 50 & 164.42 & This work \\
\hline 13 & NiO-MOF@AC 40 & 3 & 50 & 182.71 & This Work \\
\hline 14 & NiO-MOF@AC 60 & 3 & 50 & 166.28 & This work \\
\hline
\end{tabular}

Table 2. Comparison of current densities, methanol concentrations and scan rates, with other electrocatalysts reported in the literature for methanol oxidations.

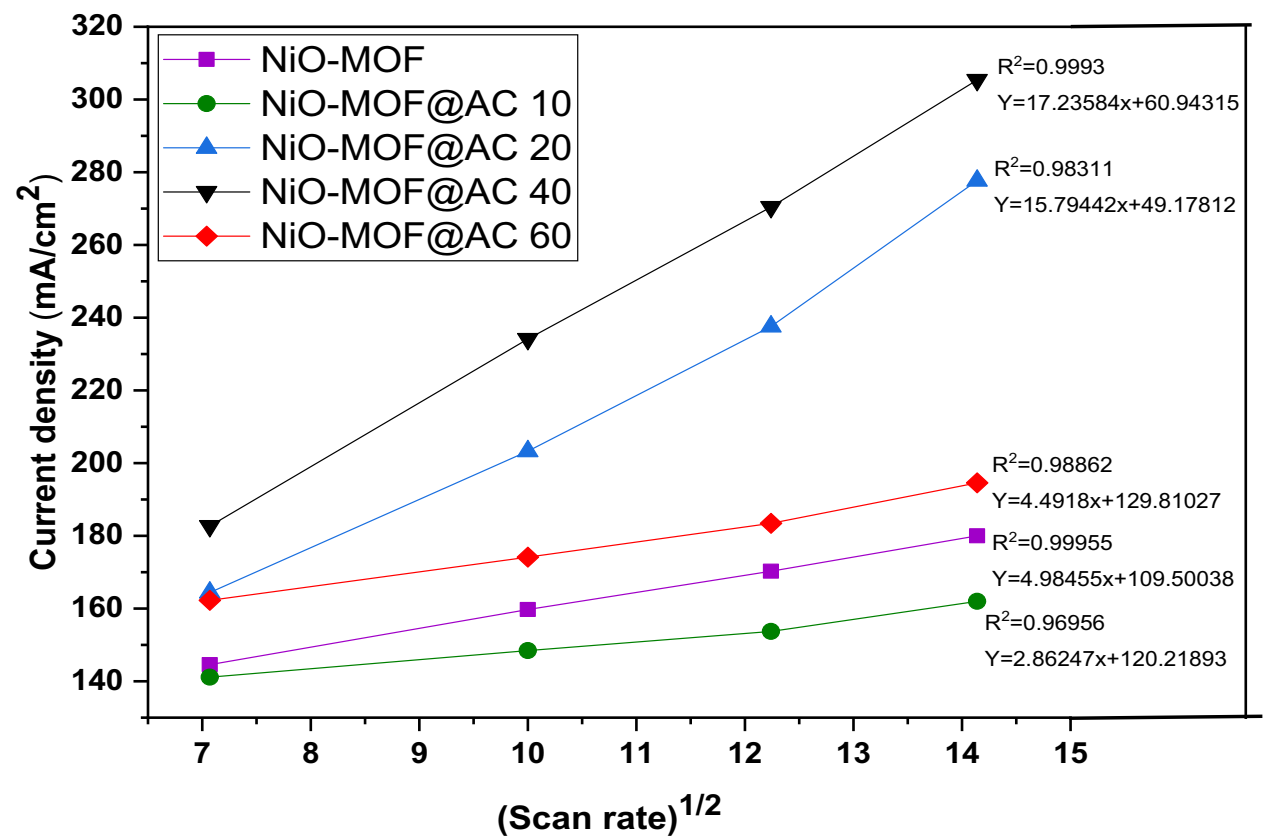

Figure 8. Plots of current density vs. square root of scan rate for NiO-MOF and its composites with activated carbon in $1 \mathrm{M} \mathrm{KOH}$ and $3 \mathrm{M}$ methanol.

of an intermediate specie such as $\mathrm{CO}^{41,42}$ Afterward with the passage of time there is gradual decrease in current and up to $3600 \mathrm{~s}$ it attain a quasi-stationary state. This possibly because of methanol coverage on catalytic site at the start of the reaction but with the reaction progress an equilibrium layer of methanol develops on the surface of catalytic sites that slows down the overall process and carbon monoxide formation effects the stability of the all the prepared electrocatalysts. Among all the prepared composites, NiO-MOF@AC 40 in accordance with its high current density shows superior percentage stability (26\%) in the set time period of $3600 \mathrm{~s}$. Next to this, $23 \%$ for NiO-MOF@AC 60,22\% for NiO-MOF@AC 20,21\% for NiO-MOF@AC 10 and 20\% for NiO-MOF. Efficient performances of all the composites clearly demonstrate that the incorporation of activated carbon in pure MOF to a certain extent will improve methanol oxidation process ${ }^{41,42}$.

\section{Conclusions}

The NiO-MOF and its biomass-derived activated carbon composites were produced by less costly and environmentally favorable hydrothermal method. The synthesized materials were tested for electrocatalytic methanol oxidation reaction. The NiO-MOF composite (Ni-MOF@AC 40) exhibited best performance with highest current density of $182.71 \mathrm{~mA} / \mathrm{cm}^{2}$ with lower over-potential values and higher stability. The NiO-MOF composite with activated carbon having non-noble metal makes it an inexpensive, but a potential candidate in the field of electrocatalysts for methanol oxidation to compete with Pt catalyst. The high current density and low cost makes it a promising alternative to the existing electrocatalyst in various fuel cell applications. 


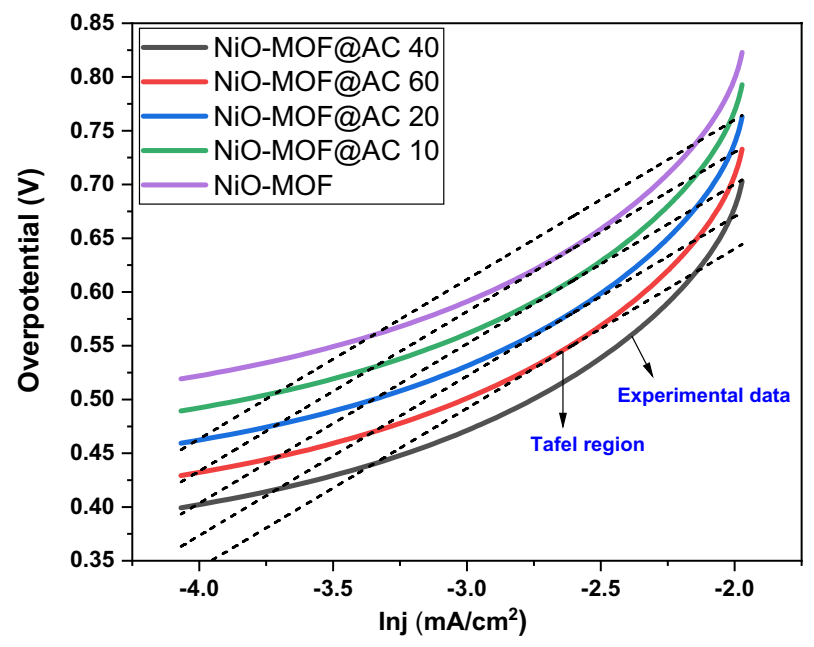

Figure 9. Tafel plots of NiO-MOF and its composites NiO-MOF@AC 10, NiO-MOF@AC 20, NiO-MOF@AC 40 and NiO-MOF@AC 60.

\begin{tabular}{|l|l|}
\hline Catalyst & Tafel slopes at $\mathbf{0 . 5 5} \mathbf{V}$ (mV/dec) \\
\hline NiO-MOF & 139 \\
\hline NiO-MOF@AC 10 & 156 \\
\hline NiO-MOF@AC 20 & 171 \\
\hline NiO-MOF@AC 40 & 121 \\
\hline NiO-MOF@AC 60 & 185 \\
\hline
\end{tabular}

Table 3. Tafel slopes of NiO-MOF and its composites such as NiO-MOF@AC 10, NiO-MOF@AC 20, NiOMOF@AC 40 and NiO-MOF@AC 60 at 0.55 V.

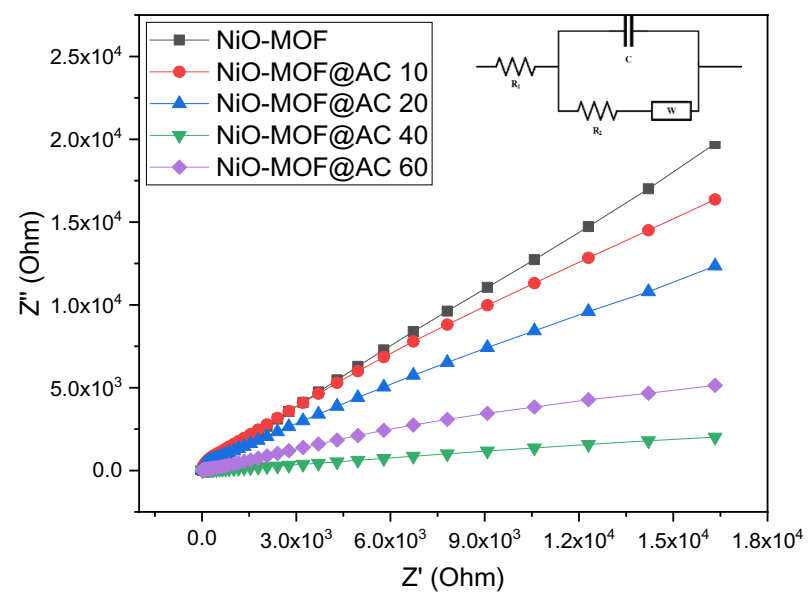

Figure 10. Nyquist plots of $\mathrm{NiO}-\mathrm{MOF}$ and the composites with activated carbon in $1 \mathrm{M} \mathrm{KOH}$ and $3 \mathrm{M}$ methanol recorded in potentiostatic mode with $50 \mathrm{mVs}^{-1}$ scan rate, $40-100 \mathrm{kHz}$ frequency range and $0.015 \mathrm{~V}$ of amplitude. 


\begin{tabular}{|l|l|l|l|l|}
\hline Sr. no & Sample & $\mathbf{R s}(\mathbf{O h m})$ & $\mathbf{R}_{\mathrm{ct}}(\mathbf{O h m})$ & Warburg diffusion co-efficient $\left(\mathbf{O h m ~ s}^{-1}\right)$ \\
\hline 1 & NiO-MOF & 53.54 & 184.3 & 9.4 \\
\hline 2 & NiO-MOF@AC 10 & 53.1 & 172.1 & 0.08 \\
\hline 3 & NiO-MOF@AC 20 & 52.9 & 168.1 & 0.05 \\
\hline 4 & NiO-MOF@AC 40 & 51.98 & 118.2 & 0.03 \\
\hline 5 & NiO-MOF@AC 60 & 53.2 & 123.2 & 0.04 \\
\hline
\end{tabular}

Table 4. Electrochemical parameters from EIS data of NiO-MOF and its composites with activated carbon (NiO-MOF@AC 10, 20, 40, 60) in $1 \mathrm{M} \mathrm{KOH}$ and $3 \mathrm{M}$ methanol solution.

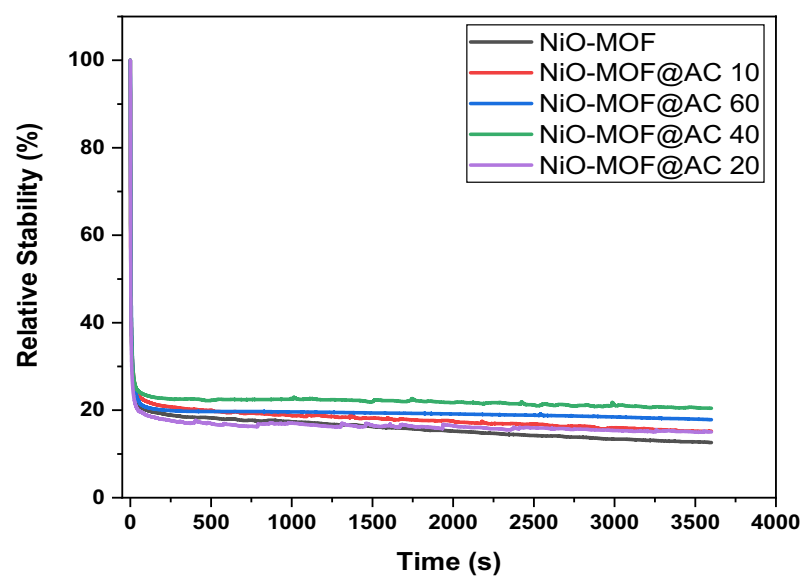

Figure 11. Relative stability curves of NiO-MOF and its composites with activated carbon in $1 \mathrm{M} \mathrm{KOH}$ and $3 \mathrm{M}$ methanol.

Received: 5 June 2021; Accepted: 6 August 2021

Published online: 25 August 2021

\section{References}

1. Bellino, M. G., Sacanell, J. G., Lamas, D. G., Leyva, A. G. \& Walsöe de Reca, N. E. High-performance solid-oxide fuel cell cathodes based on cobaltite nanotubes. J. Am. Chem. Soc. 129, 3066-3067 (2007).

2. Xia, B. Y. et al. A metal-organic framework-derived bifunctional oxygen electrocatalyst. Nat. Energy 1, 1-8 (2016).

3. Debe, M. K. J. N. Electrocatalyst approaches and challenges for automotive fuel cells. Nature 486, 43-51 (2012).

4. Wendt, H., Spinacé, E. V., Oliveira Neto, A. \& Linardi, M. J. Q. N. Electrocatalysis and electrocatalysts for low temperature fuel cells: fundamentals, state of the art, research and development. Quim. Nova 28, 1066-1075 (2005).

5. Sharma, S. \& Pollet, B. G. Support materials for PEMFC and DMFC electrocatalysts-A review. J. Power Sources 208, 96-119 (2012).

6. Chen, D. et al. Star-like PtCu nanoparticles supported on graphene with superior activity for methanol electro-oxidation. Electrochim. Acta 177, 86-92 (2015).

7. Qiu, J.-D., Wang, G.-C., Liang, R.-P., Xia, X.-H. \& Yu, H.-W. Controllable deposition of platinum nanoparticles on graphene as an electrocatalyst for direct methanol fuel cells. J. Phys. Chem. C 115, 15639-15645 (2011).

8. Liu, B., Shioyama, H., Akita, T. \& Xu, Q. Metal-organic framework as a template for porous carbon synthesis. J. Am. Chem. Soc. 130, 5390-5391 (2008).

9. James, S. L. Metal-organic frameworks. Chem. Soc. Rev. 32, 276-288 (2003).

10. Dey, C., Kundu, T., Biswal, B. P., Mallick, A. \& Banerjee, R. Crystalline metal-organic frameworks (MOFs): synthesis, structure and function. Acta Crystallogr. Sect. B Struct. Sci. Cryst. Eng. Mater 70, 3-10 (2014).

11. Meek, S. T., Greathouse, J. A. \& Allendorf, M. D. Metal-organic frameworks: A rapidly growing class of versatile nanoporous materials. Adv. Mater. 23, 249-267 (2011).

12. Shen, K., Chen, X., Chen, J. \& Li, Y. J. A. C. Development of MOF-derived carbon-based nanomaterials for efficient catalysis. ACS Catal. 6, 5887-5903 (2016).

13. Wang, H., Zhu, Q.-L., Zou, R. \& Xu, Q. J. C. Metal-organic frameworks for energy applications. Chem 2, 52-80 (2017).

14. Marković, N. \& Ross, P. N. Jr. Surface science studies of model fuel cell electrocatalysts. Surf. Sci. Rep. 45, 117-229 (2002).

15. Mehek, R. et al. Novel Co-MOF/graphene oxide electrocatalyst for methanol oxidation. Electrochim. Acta 255, 195-204 (2017).

16. Noor, T., Zaman, N., Nasir, H., Iqbal, N. \& Hussain, Z. J. E. A. Electro catalytic study of NiO-MOF/rGO composites for methanol oxidation reaction. Electrochim. Acta 307, 1-12 (2019).

17. Yaqoob, L., Noor, T., Iqbal, N., Nasir, H. \& Zaman, N. J. C. Development of nickel-BTC-MOF-derived nanocomposites with rGO towards electrocatalytic oxidation of methanol and its product analysis. Catalysts $\mathbf{9 ,} 856$ (2019).

18. Lua, A. C. \& Yang, T. Effect of activation temperature on the textural and chemical properties of potassium hydroxide activated carbon prepared from pistachio-nut shell. J. Colloid Interface Sci. 274, 594-601 (2004).

19. Jiang, G. et al. A nine-connected mixed-ligand nickel-organic framework and its gas sorption properties. Cryst. Growth Des. 11, 3713-3716 (2011).

20. Tkachev, S. et al. Reduced graphene oxide. Inorg. Mater. 48, 796-802 (2012). 
21. Kumar, A., Saxena, A., De, A., Shankar, R. \& Mozumdar, S. Controlled synthesis of size-tunable nickel and nickel oxide nanoparticles using water-in-oil microemulsions. Adv. Nat. Sci. Nanosci. Nanotechnol. 4, 025009 (2013).

22. Noor, T. et al. Nanocomposites of $\mathrm{NiO} / \mathrm{CuO}$ based MOF with $\mathrm{rGO}$ : An efficient and robust electrocatalyst for methanol oxidation reaction in DMFC. Nanomaterials 10, 1601 (2020).

23. Peng, M. M. et al. Oxidation of ethylbenzene using nickel oxide supported metal organic framework catalyst. Bull. Korean Chem. Soc. 35, 3213-3218 (2014)

24. Cao, N. \& Zhang, Y. Study of reduced graphene oxide preparation by Hummers' method and related characterization. J. Nanomater. 2015, 2 (2015)

25. Zhu, Y. et al. Graphene and graphene oxide: Synthesis, properties, and applications. Adv. Mater. 22, 3906-3924 (2010).

26. Zhang, X., Jiang, Z. H., Yao, Z. P., Song, Y. \& Wu, Z. D. Effects of scan rate on the potentiodynamic polarization curve obtained to determine the Tafel slopes and corrosion current density. Corros. Sci. 51, 581-587 (2009).

27. Shahid, M. M., Pandikumar, A., Golsheikh, A. M., Huang, N. M. \& Lim, H. N. Enhanced electrocatalytic performance of cobalt oxide nanocubes incorporating reduced graphene oxide as a modified platinum electrode for methanol oxidation. RSC Adv. 4, 62793-62801 (2014).

28. Ghouri, Z. K. et al. Nano-engineered $\mathrm{ZnO} / \mathrm{CeO}_{2}$ dots@ CNFs for fuel cell application. Arab. J. Chem. 9, 219-228 (2016).

29. Noor, T. et al. A highly efficient and stable copper BTC metal organic framework derived electrocatalyst for oxidation of methanol in DMFC application. Catal. Lett. 149, 3312-3327 (2019).

30. Cordeiro, C., De Vries, M., Cremers, T. \& Westerink, B. The role of surface availability in membrane-induced selectivity for amperometric enzyme-based biosensors. Sens. Actuators B Chem. 223, 679-688 (2016).

31. Wang, Z. et al. High electrocatalytic activity of non-noble Ni-Co/graphene catalyst for direct ethanol fuel cells. J. Solid State Electrochem. 17, 99-107 (2013)

32. Vetter, K. J. Electrochemical Kinetics: Theoretical Aspects (Elsevier, 2013)

33. Sarwar, E. et al. Effect of Co-Ni ratio in graphene based bimetallic electro-catalyst for methanol oxidation. Fuel Cells 18, 189-194 (2018).

34. Noh, Y. et al. Exploring the effects of the size of reduced graphene oxide nanosheets for Pt-catalyzed electrode reactions. Nanoscale 7, 9438-9442 (2015).

35. Tapan, N. A. \& Prakash, J. Determination of the methanol decomposition mechanism on a polycrystalline platinum electrode. Turk. J. Eng. Environ. Sci. 29, 95-104 (2005).

36. Wang, W., Li, Y. \& Wang, H. Tin oxide nanoparticle-modified commercial PtRu catalyst for methanol oxidation. Micro Nano Lett. 8, 23-26 (2013).

37. Yu, E. H., Scott, K. \& Reeve, R. W. A study of the anodic oxidation of methanol on Pt in alkaline solutions. J. Electroanal. Chem. 547, 17-24 (2003).

38. Niu, L., Li, Q., Wei, F., Chen, X. \& Wang, H. Electrochemical impedance and morphological characterization of platinum-modified polyaniline film electrodes and their electrocatalytic activity for methanol oxidation. J. Electroanal. Chem. 544, 121-128 (2003).

39. Zhu, X., Zhang, P., Xu, S., Yan, X. \& Xue, Q. Free-standing three-dimensional graphene/manganese oxide hybrids as binder-free electrode materials for energy storage applications. ACS Appl. Mater. Interfaces. 6, 11665-11674 (2014).

40. Wu, Q., Jiang, M., Zhang, X., Cai, J. \& Lin, S. A novel octahedral MnO/RGO composite prepared by thermal decomposition as a noble-metal free electrocatalyst for ORR. J. Mater. Sci. 52, 6656-6669 (2017).

41. Behmenyar, G. \& Akın, A. N. Investigation of carbon supported Pd-Cu nanoparticles as anode catalysts for direct borohydride fuel cell. J. Power Sources 249, 239-246 (2014).

42. Huang, W. et al. Highly active and durable methanol oxidation electrocatalyst based on the synergy of platinum-nickel hydroxide-graphene. Nat. Commun. 6, 10035 (2015).

\section{Acknowledgements}

The authors would like to thank the USAID (US-Pakistan Centers for Advanced Studies) for financial support. We would also like to thank PSF and NSF-Sri Lanka for the financial support under Project Nos. PSF-NSF/ Eng/C-NUST (04) and NSF-PSF/ICRP/2017/EA\&ICT/01.

\section{Author contributions}

S.H. and N.Z. did experimental work, prepared figures and wrote the manuscript N.I. T.N. and K.V. supervised experimental work and reviewed the manuscript.

\section{Competing interests}

The authors declare no competing interests.

\section{Additional information}

Correspondence and requests for materials should be addressed to N.I.

Reprints and permissions information is available at www.nature.com/reprints.

Publisher's note Springer Nature remains neutral with regard to jurisdictional claims in published maps and institutional affiliations.

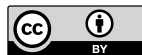

Open Access This article is licensed under a Creative Commons Attribution 4.0 International License, which permits use, sharing, adaptation, distribution and reproduction in any medium or format, as long as you give appropriate credit to the original author(s) and the source, provide a link to the Creative Commons licence, and indicate if changes were made. The images or other third party material in this article are included in the article's Creative Commons licence, unless indicated otherwise in a credit line to the material. If material is not included in the article's Creative Commons licence and your intended use is not permitted by statutory regulation or exceeds the permitted use, you will need to obtain permission directly from the copyright holder. To view a copy of this licence, visit http://creativecommons.org/licenses/by/4.0/.

(C) The Author(s) 2021 